\title{
EFFECT OF SERIES RESISTANCE ON PHOTOVOLTAIC PROPERTIES OF IN-DOPED CDTE(P) THIN FILM HOMOJUNCTION STRUCTURE
}

\author{
Wagah Farman Mohamed and Ma'an Ahmed Shehathah \\ Electrical Engineering Department \\ University of Mosul \\ Mosul - Iraq
}

\begin{abstract}
The photovoltaic properties of In-doped $\mathrm{CdTe}(\mathrm{p})$ thin film homojunction structure have been investigated, specially the effect of the series resistance on the short-circuit current at low and high light intensities has been discussed in detail. A simulation of the fabricated device is achieved successfully using the PSPICE computer program. Mathematical derivations are implemented in order to interpret the results. It is found that the deteriorative effect of the series resistance on the short circuit current versus light intensity characteristics increases with increasing the light intensity. A new factor has been suggested to measure how the series resistance affects the solar cell behavior at low and high light intensities.
\end{abstract}

\section{INTRODUCTION}

CdTe thin films have attracted attention for potential applications in the areas of solar energy conversion, gamma ray detection, and electrooptic modulator, due to their low thermal noise and large absorption coefficient [1]. A significant conversion of light into electricity has been achieved using CdTe solar cells. Recently a photovoltaic conversion efficiency of $16 \%$ has been measured. CdTe has the advantage of a nearly ideal band gap for solar cell terrestrial photoconversion $(1.5 \mathrm{eV})$, a sharp optical absorption edge, and large absorption coefficients and tolerance for relatively short minority carrier diffusion in the material [2].

The effect of Indium doping on the electrical characteristics of CdTe thin film has been studied for many years [3]. Recently, Hussien et al. [4] revealed the possibility of controlled doping with Indium for net donor concentration between $10^{15}$ and $10^{18} \mathrm{~cm}^{-3}$ in CdTe using the annealing temperature as a control factor. 


\section{Mohamed and Shehathah}

One of the important parameters that affects solar cell performance is the series resistance. As a practical matter it is generally found that the series resistance in a cell should be no more than a few tenths of an ohm for each square centimeter of illuminated cell area under one sun conditions. If this is exceeded the cell loads itself down with internal resistance [5]. The series resistance becomes more effective at high light intensities due to the high photocurrent generated [6].

In this paper we study the photovoltaic properties of In-doped $\operatorname{CdTe}(\mathrm{p})$ thin film, and the effect of the series resistance $\left(R_{s}\right)$ on the short circuit current $\left(I_{s c}\right)$, and the possibility of using this device as a solar cell.

\section{2.SOLAR CELL MODEL CHARACTERIZATION}

Since the solar cell is a semiconductor diode (without illumination), it has the characteristics of the pn junction, hence its dark current $\left(I_{d}\right)$ can be given as [6]:

$$
I_{d}=I_{o}\left(e \frac{V_{d}}{n V_{t}}-1\right)
$$

where $I_{o}$ is the saturation current, $V_{d}$ is the voltage applied across the junction, $n$ is the ideality factor, and $V_{t}$ is the thermal voltage $\left(0.026 \mathrm{~V}\right.$ at $\left.300^{\circ} \mathrm{K}\right)$.

During illumination, minority carriers flow across the junction producing a photocurrent $\left(I_{p h}\right)$. The flow of this photocurrent in an external electrical load produces a forward voltage across the cell terminals. Due to this forward bias voltage more majority carriers cross the junction producing a dark current which flows in the opposite direction to the photocurrent.

Dark current can be due to carrier injection, recombination within depletion region, and tunneling effect. If the injection current is dominant, then the ideality factor is 1 , otherwise, the ideality factor must be taken $>1$.

Solar cell can be modeled as shown in Fig . 1 taking into account the effect of series resistance $\left(R_{s}\right)$ and shunt resistance $\left(R_{s h}\right)$ [7]. The current supplied to the load (I) can be expressed as:

$$
I=I_{p h}-I_{d}-I_{s h}
$$




\section{Effect of Series Resistance on Photovoltiac Properties of In-Doped .....}

where $I_{s h}$ is the current flowing in the shunt resistor. By substituting the dark current in Eq. 1 and $I_{s h}=(V+I R s) / R_{s h}$, where $V$ is the voltage across the load $R_{L}$, Eq. 2 can be written in the form:

$$
I=I_{p h}-I_{o}\left(e \frac{V_{d}}{n V_{t}}-1\right)-\frac{V+I R_{s}}{R_{s h}}
$$

$I_{p h}, I_{o}, R_{s h}$ and $R_{s}$ are determined experimentally and fed into the PSPICE program in order to characterize the other solar cell parameters.

$$
\mathbf{R}_{8}
$$

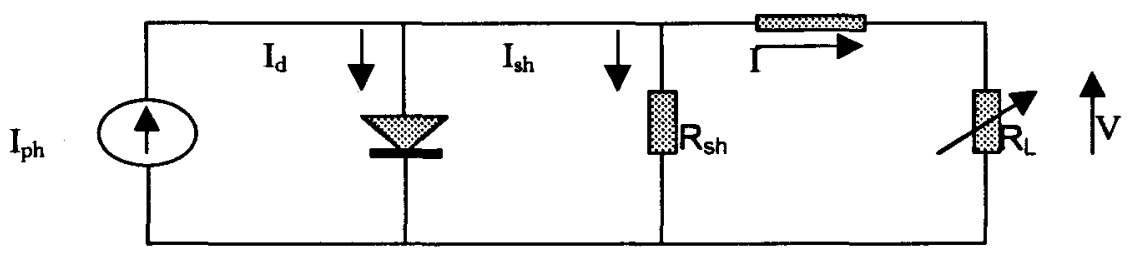

Fig.1. Solar cell model.

\section{Solar Cell Parameters Calculations}

Photons are the means by which energy is transferred to the cell. Ideally, each photon above a certain threshold energy is absorbed creating an electron-hole pair that gives rise to a single electron flowing in the external circuit. The short-circuit current depends upon the rate of generation of minority carriers within the cell and the fraction of minorities that diffuse to the junction and be collected. Theoretically, the short circuit current is equal to the photocurrent [7]. The photocurrent density $\left(J_{p h}\right)$ can be given as [8]:

$$
J_{p h}=q F(1-R)\left(1-e^{-\alpha W}\right) \eta
$$

where

$q:$ is the electronic charge.

$F:$ is the number of incident photons with energies greater than the band-gap energy $\left(E_{g}\right)$ in $\left[\mathrm{cm}^{-2} \cdot \mathrm{s}^{-1}\right]$ units.

$R$ : is the reflection coefficient.

$\alpha$ : is the absorption coefficient 


\section{Mohamed and Shehathah}

$W:$ is the thickness of the cell $[\mathrm{cm}]$.

$\eta:$ is the collection efficiency.

In general, most of the above parameters are functions of wavelength $(\lambda)$ of the incident photons. Thus a more complete equation of photocurrent density would be:

$$
J_{p h}=q \int_{\lambda} F(\lambda)(1-R(\lambda))\left(1-e^{-\alpha(\lambda) W}\right) \eta(\lambda) d \lambda
$$

The series resistance of solar cell represents the sum of all resistance elements distributed in the semiconductor, the ohmic contacts, the semiconductor contact interfaces, and the bulk resistance of the base [9]. Since the measured resistivity of the prepared CdTe film is very high $\left(10^{8} \Omega \mathrm{cm}\right)$, we shall assume that the series resistance is approximately equal to the bulk resistance of the CdTe thin film.

The saturation current $\left(I_{o}\right)$ can be estimated from DC measurements of the forward-biased diode characteristic [10]. By taking the natural logarithm of the two sides of Eq. 1, at high diode current, it becomes:

$$
\ln \left(I_{d}\right) \cong \ln \left(I_{o}\right)+\frac{V_{d}}{n V_{t}}
$$

Therefore, the ideal saturation current can be determined by the intercept with the vertical axis of the extrapolated $\ln \left(I_{d}\right)$ vs $V_{d}$ characteristic.

\section{EXPERIMENTAL DETAILS}

Few samples of In - In - doped $\operatorname{CdTe}(\mathrm{p})$ - Al structures were prepared by vacuum evaporation using Balzers unit $(\mathrm{BA}-510)$ as a coating system. A thin Aluminum layer $\left(2000^{\circ} \mathrm{A}\right)$ was deposited on a micro-glass slide followed by evaporation of CdTe layer under vacuum of $8 \times 10^{-6} \mathrm{mbar}$ at a substrate temperature $\mathrm{T}_{\mathrm{s}}=25{ }^{\circ} \mathrm{C}$, and at $20{ }^{\circ} \mathrm{A} / \mathrm{s}$ rate of deposition with thickness of $1.6584 \mu \mathrm{m}$. The deposited CdTe layer was then annealed at $350{ }^{\circ} \mathrm{C}$ for half an hour under vacuum (since the annealing process promotes the p-type of the evaporated CdTe thin film [11]). Then an Indium layer of $100^{\circ} \mathrm{A}$ was deposited on the CdTe layer to be diffused later by annealing process under vacuum, and at $85{ }^{\circ} \mathrm{C}$ annealing temperature for an hour, in order to form an In-doped CdTe (p) homojunction 
structure (see Fig. 2). The top contact is then formed by depositing a thin layer of Indium $\left(4000^{\circ} \mathrm{A}\right)$ in grid form.

In

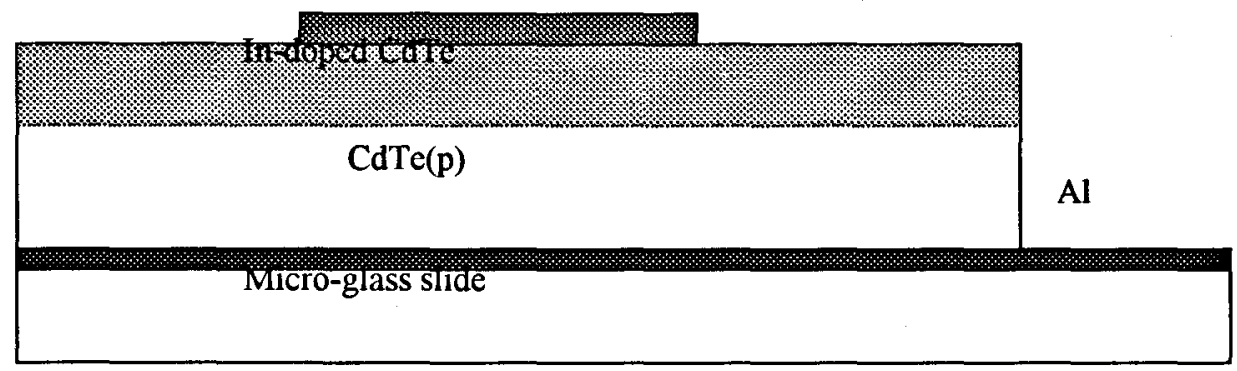

Fig. 2. A cross section in the fabricated device.

\section{RESULTS AND DISCUSSION}

Fig. 3 illustrates the I-V characteristics of the fabricated device. It is clear that the forward current is low which is attributed to the high series resistance [2].

The device has an open circuit voltage of $180 \mathrm{mV}$ at $100 \mathrm{~mW} / \mathrm{cm}^{2}$ light intensity, and low short-circuit current $\left(I_{s c}\right)$. Fig. 4 shows the variation of the measured short-circuit current with the light intensity. The low short-circuit current is due to the high bulk resistivity $\left(\rho_{b}\right)$ of the prepared film from which the bulk resistance can be calculated using the equation:

$$
R_{b}=\rho_{b} \frac{W}{A}
$$

where $R_{b}, A$, and $W$ are the bulk resistance, the area, and the thickness of the device respectively. Knowing that $A=1 \mathrm{~cm}^{2}, W=1.6583 \mu \mathrm{m}$, and $\rho_{b}=10^{8} \Omega . \mathrm{cm}$, the bulk resistance is $16.584 \mathrm{k} \Omega$ ? which is a very high. Hence, it may be considered the dominant resistance when compared with the low contact resistances, and the series resistance is approximately equal to the bulk resistance.

In Fig. 4, two regions can be recognized. For light intensity in the range 0$6 \mathrm{~mW} / \mathrm{cm}^{2}$ the short-circuit current varies rapidly comparing with that in the range $6-60 \mathrm{~mW} / \mathrm{cm}^{2}$. In other words, the increment in short circuit current $\left(\Delta l_{s c}\right)$ tends to decrease with the increase in the light intensity. It is suggested that this degradation in the cell performance at high light intensities is due to the high series resistance. 
Mohamed and Shehathah

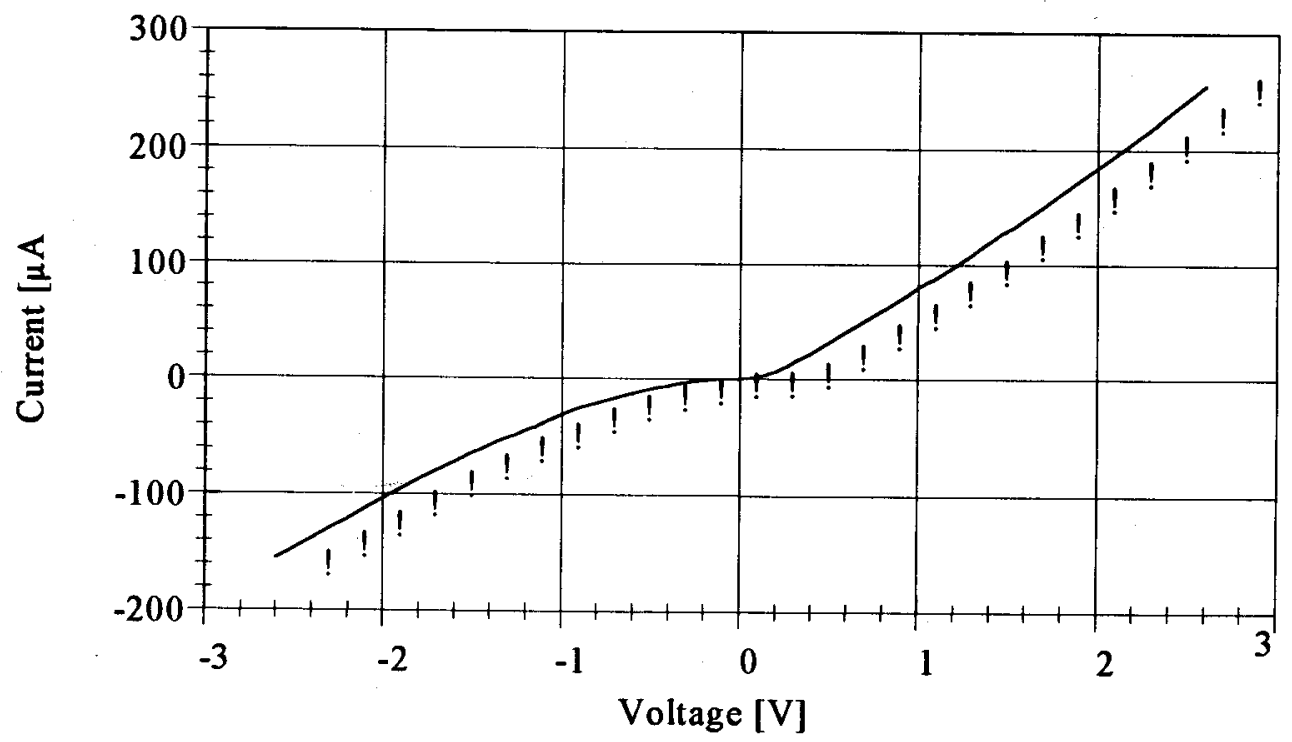

Fig. 3: I-V characteristic of In-doped CdTe(p).

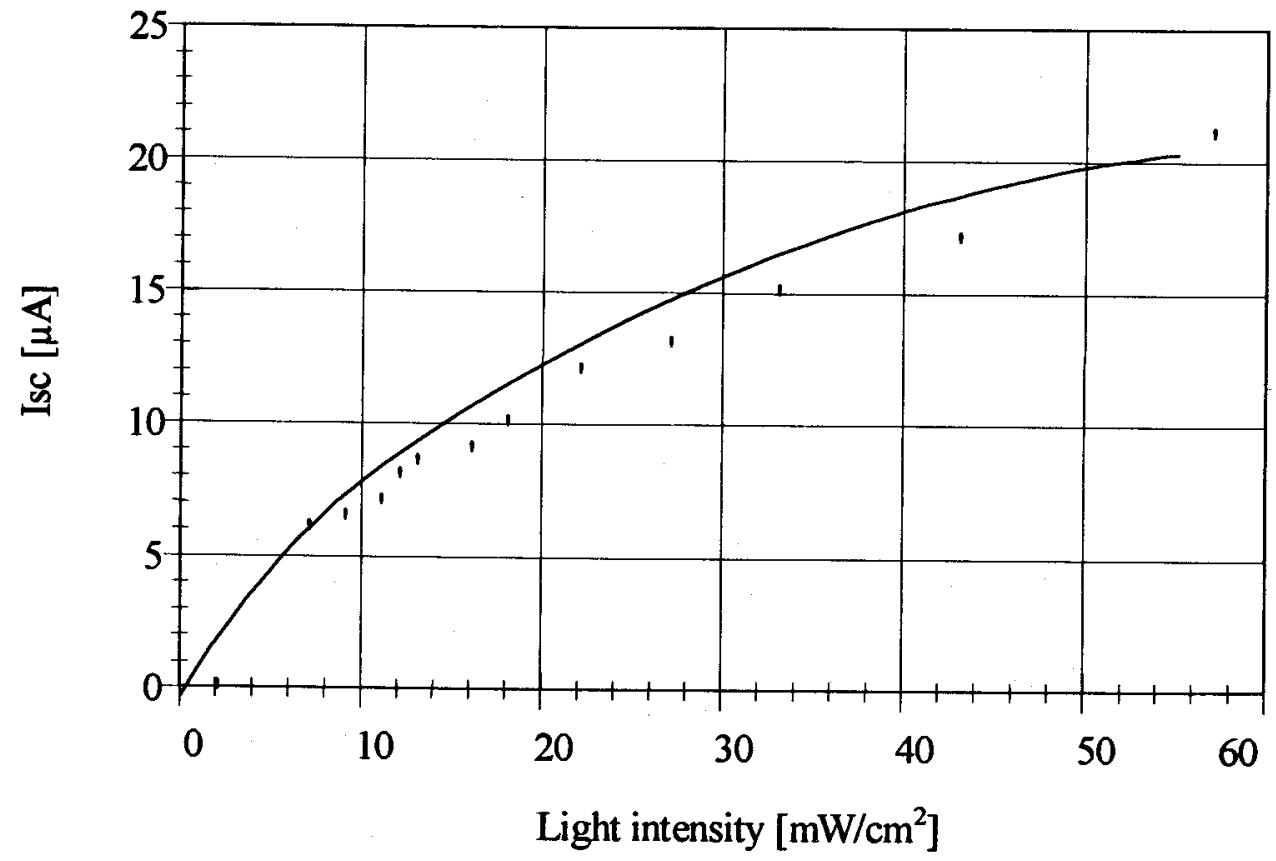

Fig. 4. Short-circuit current versus light intensity characteristic. 


\section{Effect of Series Resistance on Photovoltiac Properties of In-Doped .....}

In order to investigate the effect of series resistance on the short-circuit current at low and high light intensities, the solar cell model, shown in Fig. 1, is analyzed by the PSPICE computer program.

\section{Solar Cell Modeling by Pspice}

Today, SPICE is the circuit simulator most designers are familiar with. PSPICE can be regarded as a standard in circuit simulation [10]. In order to simulate the solar cell model, the various circuit parameters must be determined. It is found that the series resistance $R_{s}$ is equal to $16.584 \mathrm{k} \Omega$, as mentioned in section 4 , the saturation current $\left(I_{o}\right)$ is found from Fig. 5, and it is equal to $24 \mu \mathrm{A}$. The shunt resistance $\left(R_{s h}\right)$ is considered to be variable. The ideality factor $(n)$ is assumed to be equal to two (practical value). The photocurrent $\left(I_{p h}\right)$ is calculated numerically from Eq. 5 by the use of MATLAB program. It is clear that the $I_{p h}$ depends on $R(\lambda)$, $\alpha(\lambda)$, and $F(\lambda)$ as explained in Eq. 5. The collection efficiency $\eta(\lambda)$ is varied in order to calculate the variation in $I_{p h}$. When the collection efficiency varies from 0 to 1 the photocurrent varies from 0 to $37.3 \mathrm{~mA}$ (keeping in mind that the area of the device is $1 \mathrm{~cm}^{2}$ ). It is worth to mention that the limits of integration in Eq. 5 are from .45 to $.82 \mu \mathrm{m}$ (above cutoff wavelength, which is equal to $.82 \mu \mathrm{m}$ for the band gap of the $\mathrm{CdTe}\left(\mathrm{E}_{\mathrm{g}}=1.5 \mathrm{e} . \mathrm{V}\right)$, the absorption process can be ignored $)$.

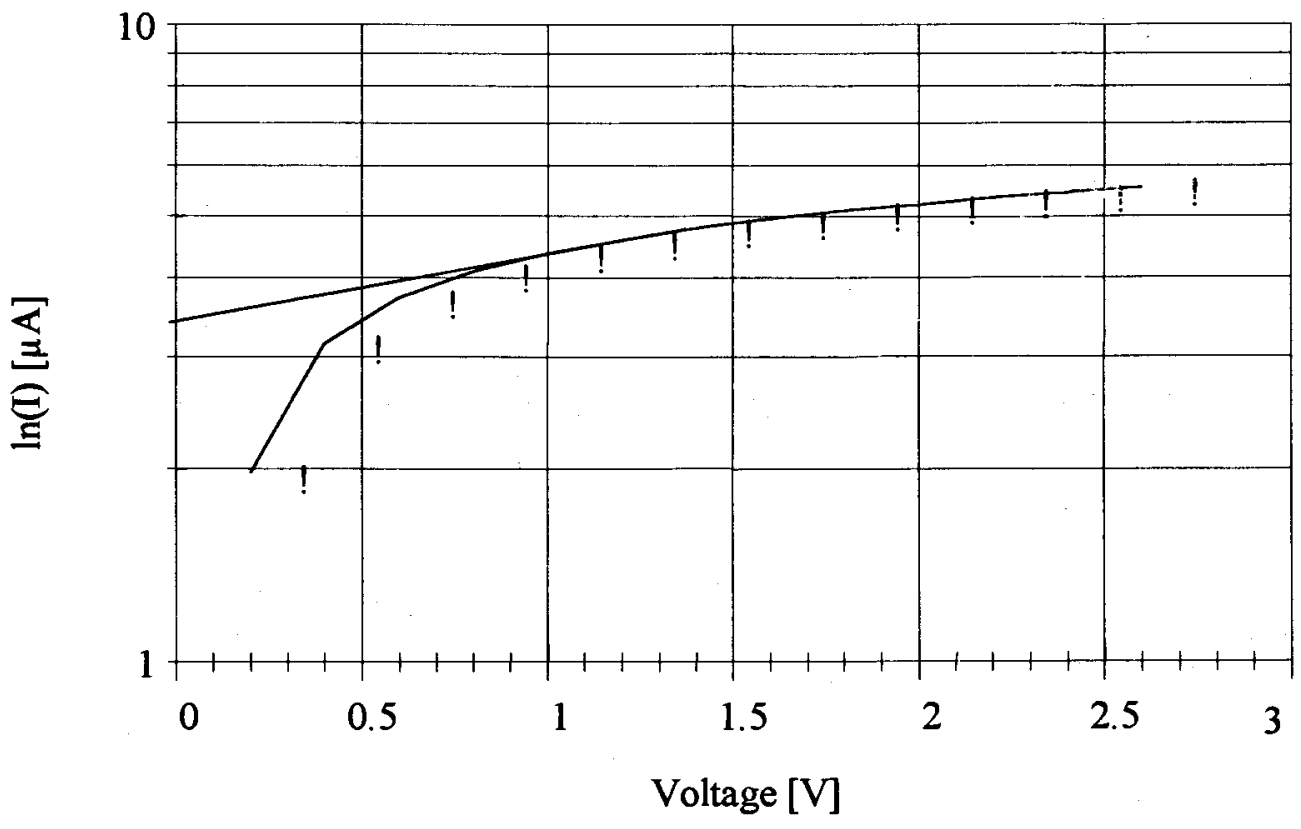

Fig. 5.The $\ln (\mathrm{I})-\mathrm{V}$ characteristic. 


\section{Mohamed and Shehathah}

The reflection coefficient of the fabricated cell is measured as a function of wavelength using a spectrophotometer, as shown in Fig. 6. The reflection coefficient is minimum in the .45 to $.55 \mu \mathrm{m}$ wavelength range and it has a maximum value in the range .7 to $.8 \mu \mathrm{m}$.

The absorption coefficient for the p-type CdTe thin film is approximated and taken from ref. 16 and shown in Fig. 7. The absorption coefficient decreases with increase in wavelength and the CdTe has sharp absorption edge. Also the spectral photon irradiance is measured experimentally as a function of wavelength as shown in Fig. 8.

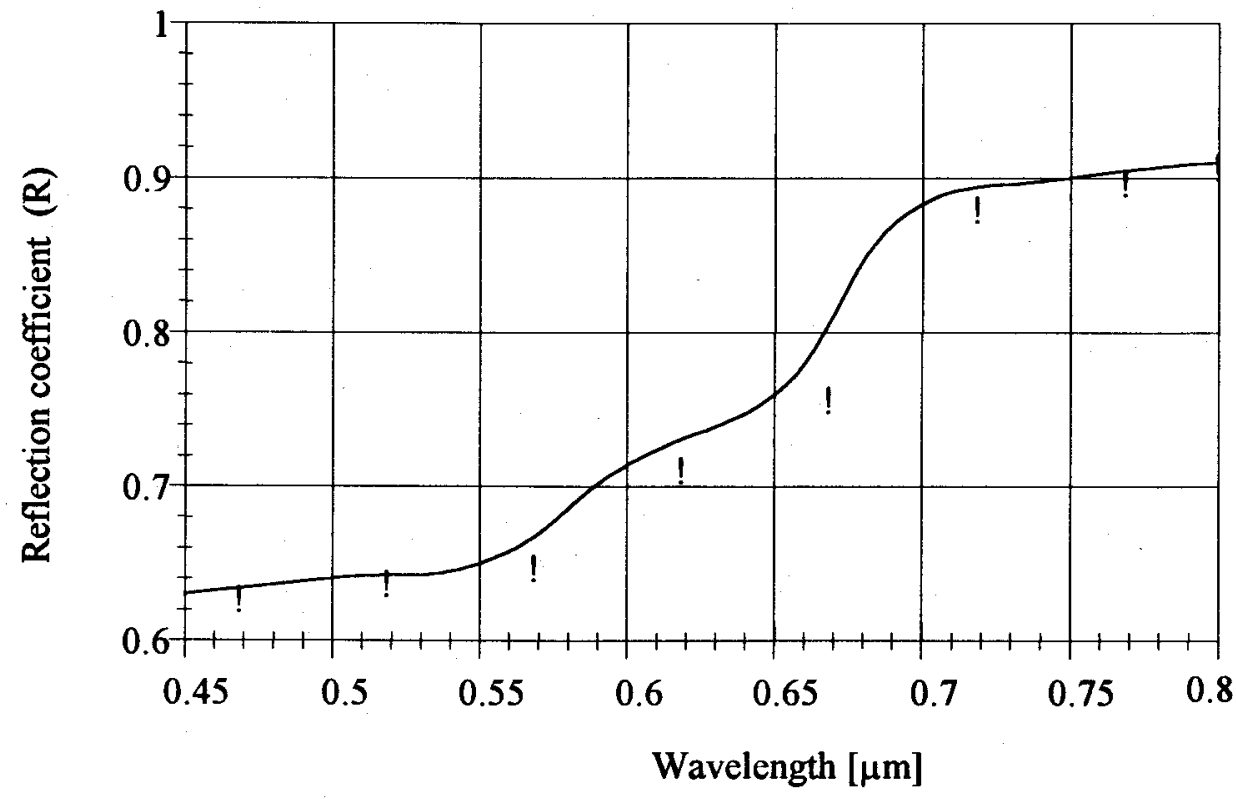

Fig. 6. Reflection coefficient versus wavelength characteristic.

\section{Mathematical Derivations}

From the above measurements, Fig. 6 to Fig. 8, and using Eq. $5, I_{p h}$ has been calculated. Using PSPICE program, the variation of short-circuit current $\left(I_{s c}\right)$ with photocurrent $\left(I_{p h}\right)$ has been calculated and is shown in Fig. 9 for different values of shunt resistance $\left(R_{s h}\right)$, and keeping the value of the series resistance constant = $16.584 \mathrm{k} \Omega$. Fig. 9 must be studied carefully because it represents the most important result in this paper. 
Effect of Series Resistance on Photovoltiac Properties of In-Doped .....

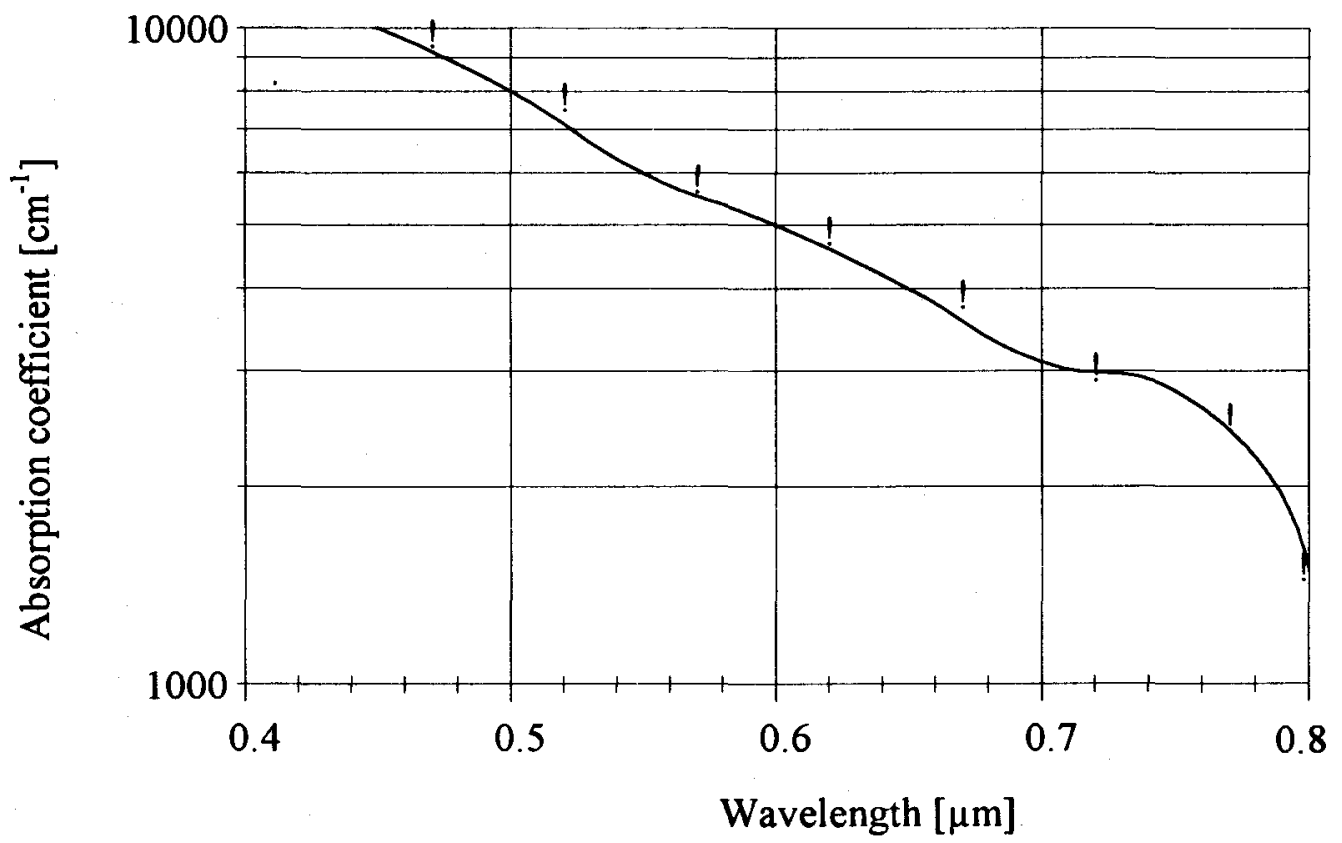

Fig. 7. Absorption coefficient versus wavelength characteristic.

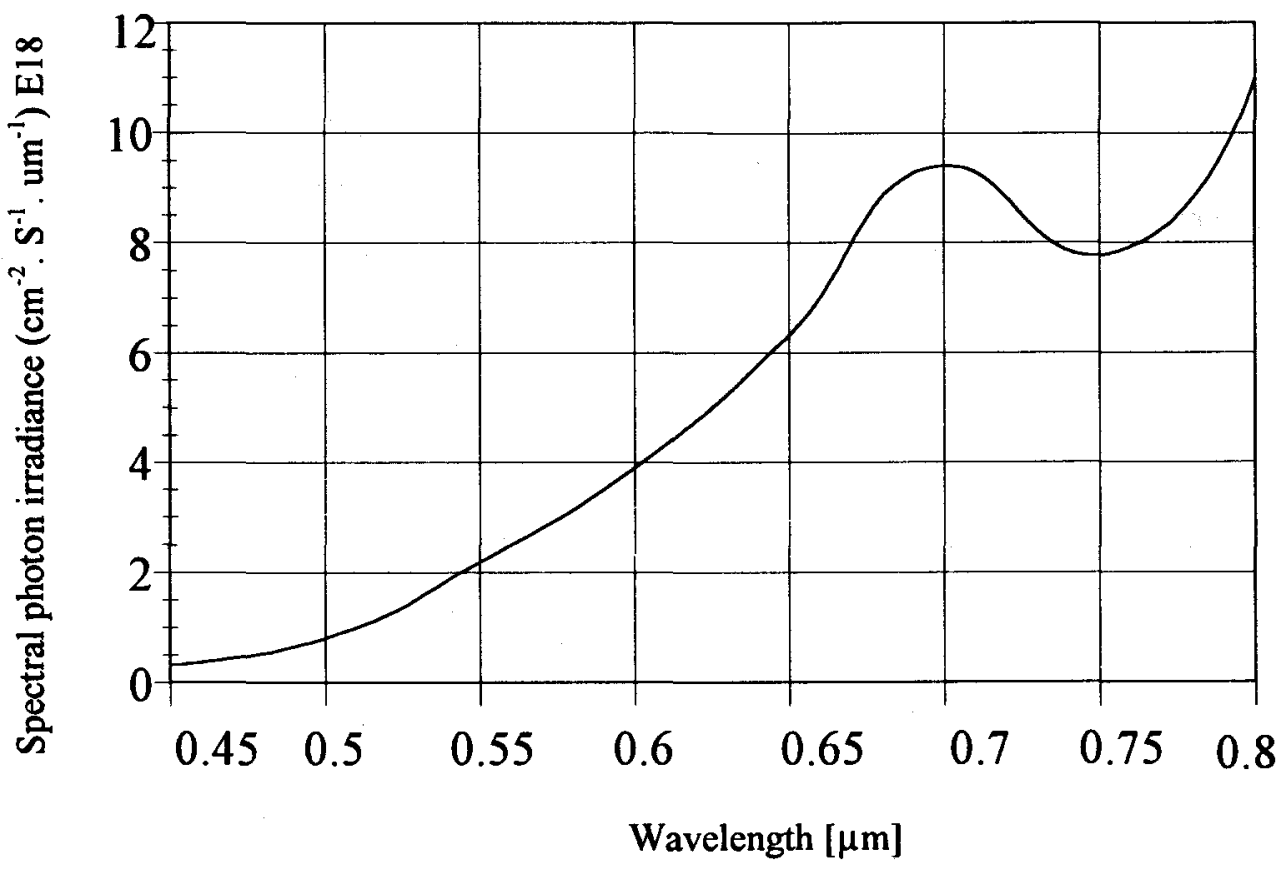

Fig. 8. Spectral photon irradiance. 


\section{Mohamed and Shehathah}

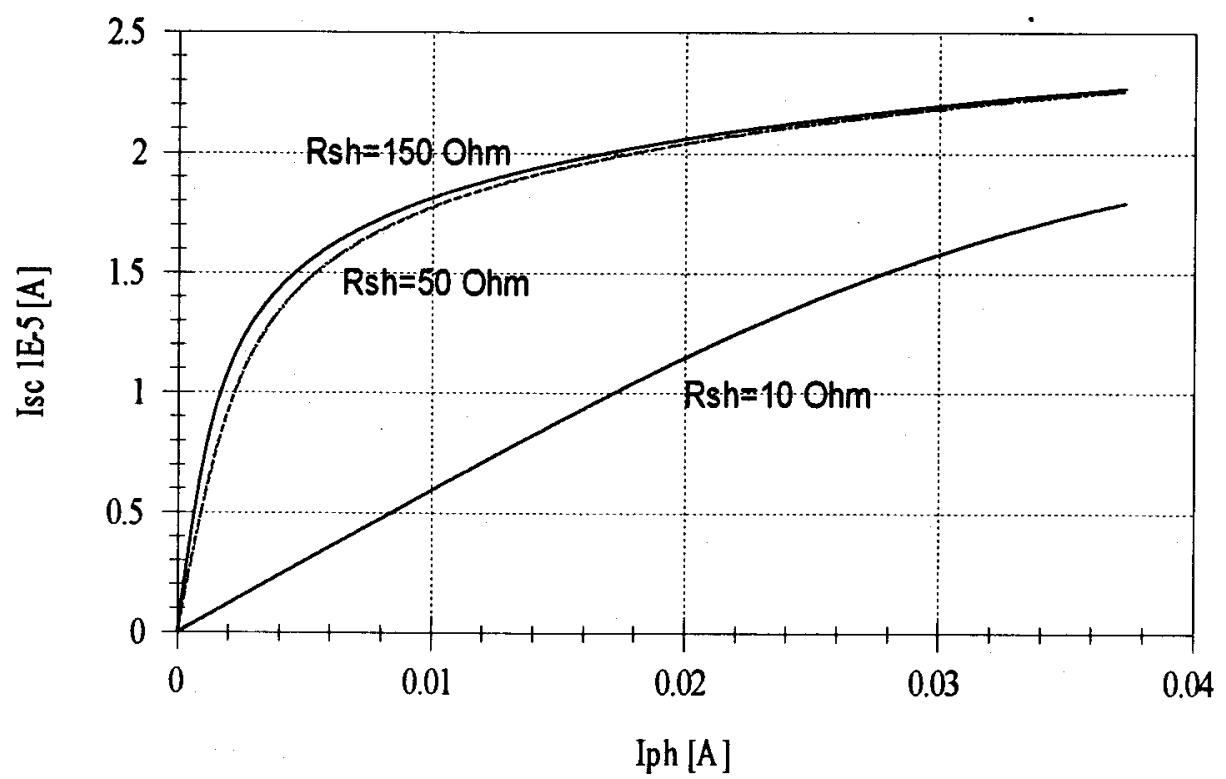

Fig. 9. $I_{s c}-I_{p h}$ characteristics for different shunt resistances.

The results obtained in Fig. 9 are approximately similar to those obtained practically in Fig. 4 for high values of the shunt resistance (since the photocurrent is proportional to the spectral photon irradiance as in Eq. 4, which in turn is proportional to the light intensity).

By the use of Eq. 3, at short-circuit current condition the voltage $(V)$ across the load $R_{L}$ becomes zero, so that Eq. 3 can be written as:

$I_{s c}=I_{p h}-I_{o}\left[e^{\left(\frac{I_{x} R_{s}}{n V_{t}}\right)}-1\right]-\frac{I_{s c} R_{s}}{R_{s h}}$

By mathematical manipulation of Eq. 8, an expression for $\left(d I_{s d} d I_{p h}\right)$ can be given as:

$\frac{d I_{s c}}{d I_{p h}}=\frac{1}{\left[1+\frac{R_{s}}{R_{s h}}\right]+\left[\frac{I_{o} R_{s}}{n V_{t}} e^{\left(\frac{I_{x} R_{s}}{n V_{t}}\right)}\right]}$ 


\section{Effect of Series Resistance on Photovoltiac Properties of In-Doped .....}

Looking back to Fig. 9, it can be observed that there are two regions in the curve for each value of the shunt resistance. One of which is of high slope (and approximately constant) at low photocurrent values, and the other is of less slope (and slightly variable) at higher photocurrent values. These two regions are compared with Eq. 9. Its denominator is composed of three terms. The first and the second terms represent a constant part (do not vary with $I_{s c}$ ), while the third term is variable (with $I_{s c}$ ). So, at very low $I_{s c}$ the constant term becomes much greater than the variable term, which is expressed as:

$$
\left.\left.1+\frac{R_{s}}{R_{s h}}\right\rangle\right\rangle \frac{I_{o} R_{s}}{n V_{t}} e^{\left(\frac{I_{x} R_{s}}{n V_{t}}\right)}
$$

then the slope is approximated to :

$$
\frac{d I_{s c}}{d I_{p h}} \cong \frac{1}{\left(1+\frac{R_{\varsigma}}{R_{s h}}\right)}=\frac{R_{h h}}{R_{h h}+R_{\zeta}}
$$

At high values of $I_{s c}$ the variable term becomes much greater than the constant term, which is expressed as:

$1+\frac{R_{s}}{R_{s h}}\left\langle\left\langle\frac{I_{o} R_{s}}{n V_{t}} e^{\left(\frac{I_{x} R_{s}}{n V_{t}}\right)}\right.\right.$

then the slope can be approximated to :

$$
\frac{d I_{s c}}{d I_{p h}} \cong \frac{1}{\frac{I_{o} R_{s}}{n V_{t}} e^{\left(\frac{I_{x} R_{s}}{n V_{t}}\right)}}
$$

It becomes obvious that at low photocurrent (low light intensity), the shortcircuit current variations depend mainly on the shunt resistance. Also the slope of the curve increases as the shunt resistance increases. But the interval between one curve and the other is decreased as the shunt resistance is increased, this is due to the limited value of the photocurrent supplied (see Fig. 1).

The above result can be interpreted consistent with Eq. 11 by keeping the series resistance constant. 


\section{Mohamed and Shehathah}

Fig. 10, which is obtained by simulation, shows the $I_{s c}-I_{p h}$ characteristics for different values of the series resistance, with shunt resistance of an arbitrary value $R_{s h}=1 \mathrm{k} \Omega$. It has been explained that Eq. 13 is derived at high light intensities (high photocurrents), which in turn means high short-circuit currents. But it is seen from Eq. 13 that the slope varies inversely with $\left(I_{o} R_{s} / n V j \exp \left(I_{s c} R_{s} / n V_{\nu}\right)\right.$, i.e. the variation of $I_{s c}$ is less as $I_{p h}$ increases due to the high effect of $R_{s}$ that is evident in Fig. 10.

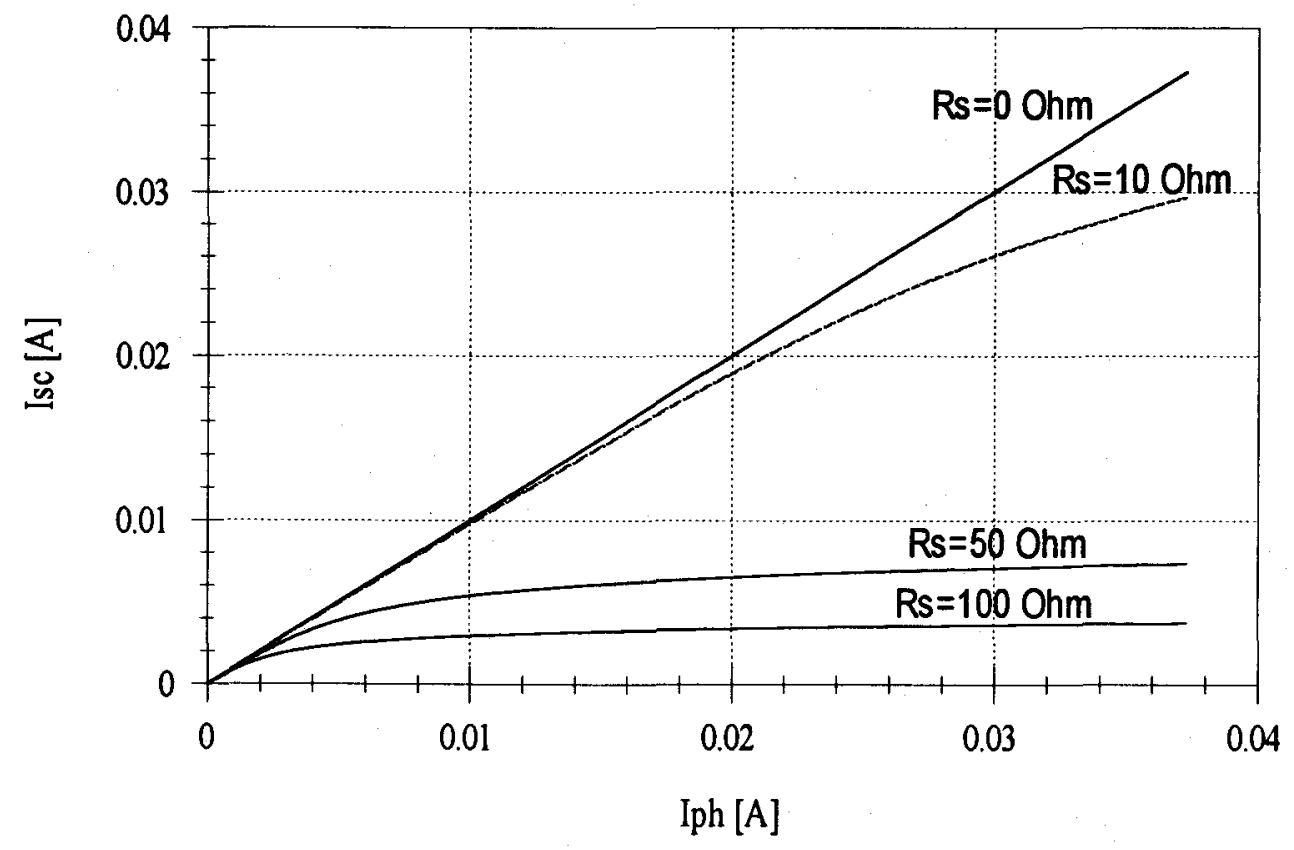

Fig. 10. $I_{s c}-I_{p h}$ characteristics for different series resistances.

To estimate the short-circuit current, below which the slope becomes constant, we solve Eq. 10 for $I_{s c}$. In order to deal with this equation, it is convenient to rewrite this equation in the following form:

$$
1+\frac{R_{s}}{R_{s h}} \geq 10 \times \frac{I_{o} R_{s}}{n V_{t}} e^{\left(\frac{I_{x} R_{s}}{n V_{t}}\right)}
$$

Solving for $\left(I_{s c}\right)$, we get: 
$I_{s c} \leq \frac{n V_{t}}{R_{s}} \ln \left[\frac{n V_{t}}{10 I_{o} R_{s}}\left(1+\frac{R_{s}}{R_{s h}}\right)\right]$

To investigate the validity of Eq. 15, Table (1) is constructed. The table includes the short-circuit current, for different shunt resistance, below which the slope is constant as measured from Fig. 9. Also, it includes the corresponding values of $I_{s c}$ that are calculated from Eq. 15 . It is obvious that the theoretical values are in good agreement with those obtained by simulation.

Table (1)

\begin{tabular}{|c|c|c|}
\hline $\begin{array}{c}\boldsymbol{R}_{\boldsymbol{s}} \\
{[\mathbf{k} ?]}\end{array}$ & $\begin{array}{c}\boldsymbol{I}_{s c} \text { (measured from simulation } \\
\text { curves shown in Fig. 9) } \\
{[? \mathbf{A}]}\end{array}$ & $\begin{array}{c}\boldsymbol{I}_{s c} \text { (calculated from } \\
\text { Eq. 15) } \\
{[? \mathbf{~ A ]}}\end{array}$ \\
\hline 16.584 & 9 & 9.6 \\
\hline 16.584 & 4.4 & 4.6 \\
\hline 16.584 & 1.1 & 1.18 \\
\hline
\end{tabular}

\section{Short Circuit Current Degradation Factor}

When the series resistance $\left(R_{s}\right)$ is zero, the short-circuit current $\left(I_{s c}\right)$ is equal to the photocurrent $\left(I_{p h}\right)$, see Fig. 1 . That is, the slope $\left(d I_{s d} d I_{p h}\right)$ will be equal to one. As the series resistance increases, its deteriorative effect on the short-circuit current increases especially at high light intensities. Here, it is important to define a "short circuit current degradation factor ". This factor gives the fraction by which the increment in the short-circuit current $\left(\Delta J_{s c}\right)$ relative to the photocurrent increment $\left(\Delta I_{p h}\right)$ is reduced due to the existence of the series resistance. This factor is denoted as $S$ and is expressed as the ratio of the slope $\Delta I_{s c} d \Delta I_{p h}$ at $R_{s}>0$ to the slope when $R_{s}$ $=0$, i.e.:

$$
S=\frac{\left[\frac{\Delta I_{s c}}{\Delta I_{p h}}\right]_{R s \neq 0}}{\left[\frac{\Delta I_{s c}}{\Delta I_{p h}}\right]_{R s=0}}
$$

Since $\Delta I_{s d} \Delta I_{p h}$ at $R_{s}=0$ is equal to one, hence the above equation can be given by: 


$$
S=\frac{d L_{c c}}{d L_{p h}}=\frac{1}{\left[1+\frac{R}{R_{h}}\right]+\left[\frac{I_{o} R}{n V} e^{\left.\frac{\left(s R_{s}\right.}{n V t}\right]}\right.}
$$

The values of this factor are obtained in the range 0 to 1 , that is, when the series resistance is zero then $S=1$ (the ideal case), and when the series resistance is infinite, $S=0$ (open circuit case).

\section{CONCLUSIONS}

The In-doped $\mathrm{CdTe}(\mathrm{p})$ thin film prepared by vacuum evaporation is of high resistivity (about $10^{8} \Omega \mathrm{m}$ ). The high resistivity largely affects the thin film photovoltaic properties, particularly the short-circuit current. The deteriorative effect of the series resistance increases by increasing the light intensity, which in turn limits the benefit of using the light concentrators that improve the short-circuit current. Mathematical derivations that depict the effect of series and shunt resistances on the short-circuit current at low and high light intensities, have been shown to be valid and can be applied to the solar cell model that has been studied and discussed in this research.

\section{REFERENCES}

1. Kim, M.D., Kang, T.W., Han, M. S. and Kim, T. W., 1996. Rapid Thermal Annealing Effects in CdTe(111)Thin Films Grown on GaAs(100) Substrates. Jpn. J. App. Phys. Vol. 35, pp. 4220-4224.

2. Al-Dhafri, A. M., 1998, Photovoltaic Properties of $\mathrm{CdTe}-\mathrm{Cu}_{2} \mathrm{Te}$. Proceedings of the Sixth Arab International Solar Energy Conference; AISEC-6, Muscat, Sultanate of Oman.

3. Watson, E., Shaw, D., 1983. The Solubility and Diffusivity of In in CdTe. J. Phys. C: Solid State Phys.,Vol. 16, pp.515-537.

4. Ahmed, H. A., Ali, L. S., 1996. Characterization of In-doped CdTe Thin Film. Mu'tah Journal for Research and Studies,Vol. 11, No. 5.pp.

5. Fonash, S. J., 1981. Solar Cell Device Physics. London, Academic press, Inc.

6. Abosh, Y. M., 1985. Theoretical Investigation of the Efficiency of Silicon Solar Cell. M. Sc. thesis, Univ. of Mosul, College of Engineering, Iraq. 
Effect of Series Resistance on Photovoltiac Properties of In-Doped ......

7. Abd Al-Hakeem, V. H., 1998. Effect of the Junction Depth and the Lifetime of the Minority Carriers on the Performance of the Solar Cell. M. Sc. thesis, Univ. of Mosul, College of Science, Iraq.

8. William, C. D., Pual, N. C., 1980. Solar Energy Hand Book. Marcel Dekker, Inc., 1980.

9. Hamoshi, A. S., 1984. Improved Efficiency $\mathrm{Cu}_{2} \mathrm{~S} / \mathrm{CdS}$ Thin Film Heterojunction Solar Cell. M. Sc. thesis, Univ. of Mosul, College of Engineering, Iraq.

10.Paolo A., Giuseppe M., 1988. Semiconductor Device Modeling with SPICE. McGraw-Hill, Inc.

11. Ou, S. S., and Stufsudd, O. M., 1984. Optical Properties of Electrochemically Deposited CdTe Films. J. App. Phys., Vol. 55, No. 10. 